\section{JURNAL EKONOMI EFEKTIF}

ISSN : $2622-8882$, E-ISSN : 2622-9935

Jurnal Ekonomi Efektif, Vol. 3, No. 2, Januari 2021 @Prodi Manajemen Fakultas Ekonomi Universitas Pamulang

\title{
PENGARUH PEMBERIAN KREDIT TERHADAP PROFITABILITAS PADA PT. BANK RAKYAT INDONESIA (PERSERO) TBK PERIODE 2012-2019
}

\author{
Arif Hidayat $^{1^{*}}$, Irfan Rizka Akbar ${ }^{2}$, Aidil Amin Effendi ${ }^{3}$ \\ Universitas Pamulang, Tangerang Selatan, Banten, Indonesia \\ dosen02519@unpam.ac.id*
}

Manuskrip: Nov-2020; Ditinjau: Nov-2020; Diterima: Nov-2020; Online: Jan-2021; Diterbitkan: Jan-2021

\begin{abstract}
ABSTRAK
Penelitian ini bertujuan untuk mengetahui pengaruh Pemberian kredit terhadap Profitabilitas pada PT. Bank Rakyat Indonesia (Persero) Tbk. Metode yang digunakan adalah explanatory research. Teknik analisis menggunakan analisis statistik dengan pengujian regresi, korelasi, determinasi dan uji hipotesis. Hasil penelitian ini variabel Pemberian kredit diperoleh nilai rata-rata sebesar 3,81\%. Variabel Profitabilitas diperoleh nilai rata-rata 3,91\%. Pemberian kredit berpengaruh positif dan signifikan terhadap Profitabilitas dengan nilai persamaan regresi $\mathrm{Y}=9,701+0,326 \mathrm{X}$, dan nilai koefisien korelasi 0,649 atau memiliki tingkat hubungan yang kuat dengan nilai determinasi 42,1\%. Uji hipotesis diperoleh signifikansi $0,000<0,05$.
\end{abstract}

\section{Kata Kunci: Pemberian Kredit, Profitabilitas.}

\begin{abstract}
This study aims to determine the effect of lending on profitability at PT. Bank Rakyat Indonesia (Persero) Tbk. The method used is explanatory research. The analysis technique uses statistical analysis with regression testing, correlation, determination and hypothesis testing. The results of this study, the variable of giving credit obtained an average value of $3.81 \%$. The profitability variable obtained an average value of $3.91 \%$. Lending has a positive and significant effect on profitability with a regression equation value of $Y=9.701+0.326 X$, and a correlation coefficient value of 0.649 or having a strong level of relationship with a determination value of $42.1 \%$. Hypothesis testing obtained a significance of $0.000<0.05$.
\end{abstract}

Keywords: Lending, Profitability. 


\section{PENDAHULUAN}

\section{A. Latar Belakang Masalah}

Pada umumnya suatu negara diharapkan dapat meningkatkan perekonomian dalam rangka meningkatkan taraf hidup masyarakatnya melalui adanya kebijakan dibidang perekonomian negara tersebut. Berbagai unsur pembangunan dibidang ekonomi dan keuangan menjadi salah satu faktor penentu perekonomian negara, kegiatan dunia usaha merupakan cerminan perekonomian bagi suatu daerah dalam meningkatkan pendapatan guna mencapai kesejahteraan masyarakat. Salah satu unsur kegiatan pembangunan ekonomi dan keuangan adalah lembaga keuangan, lembaga keuangan yang dimaksud adalah bank.

Menurut Undang-Undang RI Nomor 10 Tahun 1998 tanggal 10 November 1998 tentang perbankan, bahwa "Bank adalah badan usaha yang menghimpun dana dari masyarakat dalam bentuk simpanan dan menyalurkannya kembali kepada masyarakat dalam bentuk kredit dan atau bentuk-bentuk lainnya dalam rangka meningkatkan taraf hidup rakyat banyak.". Bank juga merupakan suatu badan yang berfungsi sebagai financial intermediary atau perantara keuangan antara pemilik dana dengan pengguna dana. Keterikatan yang semakin erat antara bank dan uang, maka bank disebut juga sebagai suatu lembaga yang berniaga uang Dalam kegiatan operasionalnya, bank harus selalu inovatif agar dapat selalu mempertahankan kegiatan usahanya yang bertujuan pada peningkatan taraf hidup rakyat banyak seperti halnya fungsi bank adalah menghimpun dana dari masyarakat dan selanjutnya disalurkan kembali melalui pemberian kredit pada masyarakat yang membutuhkannya. Kredit merupakan penyediaan uang atau tagihan berdasarkan persetujuan pinjam meminjam yang mewajibkan untuk melunasinya dalam jangka waktu tertentu dengan pemberian bunga.

Peranan bank sebagai lembaga keuangan tidak pernah lepas dari masalah kredit, berbagai sumber dana yang telah dihimpun oleh bank dari masyarakat sebagian besar dialokasikan untuk kredit. Kegiatan kredit merupakan rangkaian kegiatan utama suatu bank besarnya jumlah kredit yang disalurkan akan menentukan keuntungan bagi bank, karena dengan pemberian kredit akan berdampak positif yaitu penambahan dana yang terjadi dari kegiatan pembayaran para nasabah bank.

Pengelolaan kredit bagi sebuah perusahaan adalah suatu hal yang penting untuk dilakukan agar kreditnya berjalan dengan baik dan meminimalkan hal-hal yang mungkin akan terjadi diluar perhitungan. Melakukan pengelolaan kredit berarti melaksanakan fungsi-fungsi manajemen, dimana dalam mengelola atau mengatur kreditnya perlu dilakukan perencanaan yang matang. Kemudian setelah direncanakan maka diorganisasikan, agar perencanaan tersebut lebih terarah. Pelaksanaan pengelolaan kredit dapat meningkatkan keuntungan bagi sebuah perusahaan. Memperoleh keuntungan merupakan tujuan utama berdirinya suatu badan usaha, baik badan usaha yang terbentuk perseroan terbatas (PT), yayasan atau bentuk badan usaha lainnya.

Menurut Kasmir (2010:245) bahwa "Kegiatan utama bank adalah menyalurkan dana, maka jika dikatakan bahwa apabila pinjaman meningkat, maka dalam praktiknya akan mampu meningkatkan laba perusahaan. Demikin pula sebaliknya apabila tidak mampu menyalurkan kreditnya, maka bank akan rugi karena beban biaya untuk penimpanan dana tetap harus dibayarkan. Keuntungan yang diterima bank berasal dari selisih bunga pinjaman kepada debitur dengan suku bunga simpanan yang dibayar kepada nasabah penyimpan (Abdullah, 2005:32). Jika kredit yang disalurkan kepada masyarakat semakin besar maka pendapatan yang di terima bank akan meningkat dan akan mempengaruhi besarnya laba yang diterima oleh bank tersebut.

Profitabilitas merupakan kemampuan suatu perusahaan untuk mendapatkan laba 
(keuntungan) dalam suatu periode tertentu. Pengertian yang sama juga disampaikan oleh Husnan (2001) bahwa profitabilitas adalah kemampuan suatu perusahaan dalam menghasilkan keuntungan (Profit) pada tingkat penjualan, aset, modal saham tertentu. Sedangkan menurut Michelle Megawati (2005) profitabilitas merupakan kemampuan perusahaan menghasilkan laba(profit) yang akan menjadi dasar pembagian deviden perusahaan.

Dalam hal penilaian tingkat profitabilitas suatu bank yang diukur dalam aktiva produktif yang sumber dananya berasal dari kredit yang diberikan kepada masyarakat yang dapat membantu bank dalam memaksimumkan profitabilitasnya yang salah satu indikatornya adalah return on assets (ROA). Besarnya jumlah kredit yang disalurkan akan menentukan keuntungan yang diperolah. Akan tetapi tidak berarti bahwa jumlah kredit yang disalurkan besar akan memberikan keuntungan yang besar pula. Dalam hal ini PT. Bank Rakyat Indonesia (Persero), Tbk atau bank BRI adalah salah satu bank milik pemerintah yang terbesar di Indonesia yang memberikan kontribusi signifikan terhadap perbankan dan perekonomian Indonesia. Bank selalu menerapkan prinsip hati-hati dalam pemberian kredit agar laba yang diharapkan oleh bank tersebut terus meningkat, prinsip hati-hati dapat dilihat dari peningkatan pengawasan pemberian kredit dan penurunan resiko kredit bermasalah.

Tabel 1. Data Kredit Yang Disalurkan Berserta Perolehan Profitabilitas PT. Bank Rakyat Indonesia (Persero), Tbk dari tahun 2012 sampai dengan 2019

\begin{tabular}{|c|c|c|c|c|}
\hline Tahun & Total Asset & $\begin{array}{c}\text { Kredit Yang } \\
\text { Diberikan }\end{array}$ & $\begin{array}{c}\text { Laba Sebelum } \\
\text { Pajak }\end{array}$ & $\begin{array}{c}\text { Profitabilitas } \\
\text { (ROA) } \%\end{array}$ \\
\hline 2012 & 404.285 & 232.972 & 14.908 & 4.13 \\
\hline 2013 & 469.899 & 269.455 & 18.755 & 4.29 \\
\hline 2014 & 551.336 & 336.081 & 23.859 & 4.91 \\
\hline 2015 & 626.132 & 419.144 & 27.915 & 5.74 \\
\hline 2016 & 801.955 & 479.211 & 30.859 & 5.32 \\
\hline 2017 & 878.426 & 547.318 & 32.494 & 5.87 \\
\hline 2018 & 612.335 & 415.335 & 28.545 & 4.25 \\
\hline 2019 & 755.436 & 435.525 & 16.855 & 4.65 \\
\hline
\end{tabular}

Berdasarkan tabel di atas penulis tertarik untuk meneliti PT. Bank Rakyat Indonesia (Persero), Tbk karena latar belakang perusahaan sebagai salah satu perusahaan dibidang perbankan di Indonesia dimana yang menjadi salah satu aset ekonomi negara yang mengelola dan menyalurkan dana dari masyarakat kepada masyarakat dengan cara kredit. Dengan menggunakan rasio Profitabilitas penulis ingin mengetahui sejauh mana pengaruh pemberian kredit terhadap laba yang dihasilkan perusahaan tersebut.

Berdasarkan latar belakang diatas maka penulis tertarik untuk mengambil judul penelitian "Pengaruh Pemberian Kredit Terhadap Profitabilitas Pada PT. Bank Rakyat Indonesia (Persero) Tbk".

\section{B. Rumusan Masalah}

1. Bagaimana Pemberian kredit pada pada PT. Bank Rakyat Indonesia (Persero) Tbk?.

2. Bagaimana Profitabilitas pada PT. Bank Rakyat Indonesia (Persero) Tbk ?.

3. Adakah pengaruh antara Pemberian kredit terhadap Profitabilitas pada PT. Bank Rakyat Indonesia (Persero) Tbk?.

\section{Tujuan Penelitian}

1. Untuk mengetahui kondisi Pemberian kredit pada PT. Bank Rakyat Indonesia (Persero) Tbk.

2. Untuk mengetahui kondisi Profitabilitas pada PT. Bank Rakyat Indonesia (Persero) 
Tbk.

3. Untuk mengetahui pengaruh antara Pemberian kredit terhadap Profitabilitas pada PT. Bank Rakyat Indonesia (Persero) Tbk

\section{METODE PENELITIAN}

\section{Populasi}

Populasi dalam penelitian ini laporan keuangan PT. Bank Rakyat Indonesia (Persero) Tbk selama 8 tahun

\section{Sampel}

Teknik pengambilan sampling dalam penelitian ini adalah samplel jenuh, dimana semua anggota populasi dijadikan sebagai sampel. Dengan demikian sampel dalam penelitian ini laporan keuangan PT. Bank Rakyat Indonesia (Persero) Tbk selama 8 tahun.

\section{Jenis Penelitian}

Jenis penelitian yang dipakai adalah asosiatif, dimana tujuannya adalah untuk mengetahui mencari keterhubungan antara variabel independen terhadap variabel dependennya

\section{Metode Analisis Data}

Dalam menganalisis data digunakan uji validitas, uji reliabilitas, analisis regresi linier sederhana, koefisien korelasi, koefisien determinasi dan uji hipotesis.

\section{HASIL PENELITIAN DAN PEMBAHASAN}

\section{Analisis Deskriptif}

Pada pengujian ini digunakan untuk mengetahui skor minimum dan maksimum skor tertinggi, ratting score dan standar deviasi dari masing-masing variabel. Adapun hasilnya sebagai berikut:

Tabel 1. Hasil Analisis Descriptive Statistics

Descriptive Statistics

N Minimum Maximum Mean Std. Deviation

\begin{tabular}{|l|r|r|r|r|r}
\hline Pemberian kredit (X) & 8 & 232.97 & 547.32 & 391.88 & 105.789 \\
\hline Profitabilitas (Y) & 8 & 4.13 & 5.87 & 4.89 & .683 \\
\hline Valid N (listwise) & 8 & & & & \\
\hline
\end{tabular}

Pemberian kredit diperoleh nilai minimum sebesar 32 dan nilai maximum 48 dengan rata-rata sebesar 3,81 dengan standar deviasi 4,019. Profitabilitas diperoleh nilai minimum sebesar 32 dan nilai maximum 48 dengan rata-rata sebesar 3,91 dengan standar deviasi 4,019

\section{Analisis Verifikatif.}

Pada analisis ini dimaksudkan untuk mengetahui pengaruh variabel independen terhadap variabel dependen. Adapun hasil pengujian sebagai berikut:

\section{a. Analisis Regresi Linier Sederhana}

Uji regresi ini dimaksudkan untuk mengetahui perubahan variabel dependen jika variabel independen mengalami perubahan. Adapun hasil pengujiannya sebagai berikut:

Tabel 2. Hasil Pengujian Regresi Linier Sederhana

\section{Coefficients ${ }^{\mathrm{a}}$}

\begin{tabular}{|c|c|c|c|c|c|}
\hline \multirow[b]{2}{*}{ Model } & \multicolumn{2}{|c|}{$\begin{array}{l}\text { Unstandardized } \\
\text { Coefficients }\end{array}$} & \multirow{2}{*}{$\begin{array}{c}\text { Standardized } \\
\text { Coefficients } \\
\text { Beta } \\
\end{array}$} & \multirow[b]{2}{*}{$\mathrm{t}$} & \multirow[b]{2}{*}{ Sig. } \\
\hline & $\mathrm{B}$ & Std. Error & & & \\
\hline 1 (Constant) & 2.991 & .703 & & 4.253 & .005 \\
\hline
\end{tabular}




\begin{tabular}{l|l|l|l|l|l|}
$\begin{array}{l}\text { Pemberian kredit } \\
(\mathrm{X})\end{array}$ & .005 & .002 & .752 & 2.793 & .031 \\
\hline
\end{tabular}

Berdasarkan hasil pengujian pada tabel di atas, diperoleh persamaan regresi $\mathrm{Y}$ $=9,701+0,326 X$. Dari persamaan tersebut dijelaskan sebagai berikut:

1) Konstanta sebesar 9,701 diartikan jika Pemberian kredit tidak ada, maka telah terdapat nilai Profitabilitas sebesar 9,701 point.

2) Koefisien regresi Pemberian kredit sebesar 0,326, angka ini positif artinya setiap ada peningkatan Pemberian kredit sebesar 0,326 point maka Profitabilitas juga akan mengalami peningkatan sebesar 0,326 point.

\section{b. Analisis Koefisien Korelasi}

Analisis koefisien korelasi dimaksudkan untuk mengetahui tingkt kekuatan hubungan dari variabel independen terhadap variabel dependen baik secara parsial maupun simultan. Adapun hasil pengujian sebagai berikut:

Tabel 3. Hasil Pengujian Koefisien Korelasi Pemberian kredit Terhadap

\section{Profitabilitas.}

Correlations $^{\mathbf{b}}$

\begin{tabular}{llr|r} 
& \multicolumn{2}{c}{ Pemberian kredit (X1) } & Profitabilitas (Y) \\
\hline Pemberian kredit (X) & Pearson Correlation & 1 & $.752^{*}$ \\
\cline { 2 - 4 } & Sig. (2-tailed) & & .031 \\
\hline Profitabilitas (Y) & Pearson Correlation & $.752^{*}$ & 1 \\
\cline { 2 - 4 } & Sig. (2-tailed) & .031 & \\
\hline
\end{tabular}

Berdasarkan hasil pengujian diperoleh nilai korelasi sebesar 0,649 artinya Pemberian kredit memiliki hubungan yang kuat terhadap Profitabilitas.

\section{c. Analisis Koefisien Determinasi}

Analisis koefisien determinasi dimaksudkan untuk mengetahui besarnya persentase pengaruh dari variabel independen terhadap variabel dependen. Adapun hasil pengujian sebagai berikut:

Tabel 4. Hasil Pengujian Koefisien Determinasi Pemberian kredit Terhadap

Profitabilitas.

Model Summary

\begin{tabular}{ll|l|l|l} 
Model & $\mathrm{R}$ & $\mathrm{R}$ Square & Adjusted R Square & Std. Error of the Estimate
\end{tabular}

\begin{tabular}{lrr|rr}
\hline 1 & $.752^{\mathrm{a}}$ & .565 & .493 & .48699 \\
\hline
\end{tabular}

Berdasarkan hasil pengujian diperoleh nilai determinasi sebesar 0,421 artinya Pemberian kredit memiliki kontribusi pengaruh sebesar 42,1\% terhadap Profitabilitas.

\section{d. Uji Hipotesis}

Pengujian hipotesis dengan uji t digunakan untuk mengetahui hipotesis mana yang diterima. Rumusan hipotesis: Terdapat pengaruh yang signifikan antara Pemberian kredit terhadap Profitabilitas.

Tabel 5. Hasil Uji Hipotesis Pemberian kredit Terhadap Profitabilitas.

\section{Coefficients ${ }^{\mathrm{a}}$}

\begin{tabular}{|c|c|c|c|c|c|}
\hline \multirow[b]{2}{*}{ Model } & \multicolumn{2}{|c|}{$\begin{array}{l}\text { Unstandardized } \\
\text { Coefficients }\end{array}$} & \multirow{2}{*}{$\begin{array}{c}\text { Standardized } \\
\text { Coefficients } \\
\text { Beta }\end{array}$} & \multirow[t]{2}{*}{$\mathrm{t}$} & \multirow[t]{2}{*}{ Sig. } \\
\hline & $\mathrm{B}$ & Std. Error & & & \\
\hline 1 (Constant) & 2.991 & .703 & & 4.253 & .005 \\
\hline Pemberian kredit (X) & .005 & .002 & .752 & 2.793 & .031 \\
\hline
\end{tabular}

Berdasarkan hasil pengujian pada tabel di atas, diperoleh nilai t hitung $>\mathrm{t}$ tabel atau $(7,809>2,447)$, dengan demikian hipotesis yang diajukan bahwa terdapat 
pengaruh yang signifikan atara Pemberian kredit terhadap Profitabilitas diterima.

\section{PEMBAHASAN HASIL PENELITIAN}

\section{Kondisi Jawaban Responden Variabel Pemberian Kredit}

Berdasarkan data empiris dan analisis data, variabel Pemberian kredit diperoleh nilai rata-rata per tahun sebesar $3,81 \%$.

\section{Kondisi Jawaban Responden Variabel Profitabilitas}

Berdasarkan data empiris dan analisis data, variabel Profitabilitas diperoleh nilai rata-rata per tahun sebesar 3,91\%.

\section{Pengaruh Pemberian kredit Terhadap Profitabilitas}

Pemberian kredit berpengaruh signifikan terhadap Profitabilitas dengan persamaan regresi $\mathrm{Y}=9,701+0,326 \mathrm{X}$, nilai korelasi sebesar 0,649 atau memiliki hubungan yang kuat dengan kontribusi pengaruh sebesar $42,1 \%$. Pengujian hipotesis diperoleh nilai $\mathrm{t}$ hitung $>\mathrm{t}$ tabel atau $(7,809>2,447)$. Dengan demikian hipotesis yang diajukan bahwa terdapat berpengaruh signifikan antara Pemberian kredit terhadap Profitabilitas diterima.

\section{PENUTUP}

\section{Kesimpulan}

a. Kondisi variabel Pemberian kredit berdasar pada periode laporan keuangan 8 tahun diperoleh Pemberian kredit rata-rata sebesar 3,81.

b. Kondisi variabel Profitabilitas berdasar pada periode laporan keuangan 8 tahun diperoleh Pemberian kredit rata-rata sebesar 3,91.

c. Pemberian kredit berpengaruh signifikan terhadap Profitabilitas dengan persamaan regresi $\mathrm{Y}=9,701+0,326 \mathrm{X}$, nilai korelasi sebesar 0,649 atau kuat dan kontribusi pengaruh sebesar $42,1 \%$ sedangkan sisanya sebesar $57,9 \%$ dipengaruhi faktor lain. Uji hipotesis diperoleh nilai t hitung $>\mathrm{t}$ tabel atau $(7,809>2,447)$.

\section{Saran}

a. Sebaiknya perusahaan selalu memiliki strategi baru dan inovasi baru untuk meningkatkan jumlah pemberian kredit agar setiap tahunnya mengalami peningkatan.

b. Sebaiknya Perusahaan mengelola aset yang dihasilkan dengan baik, karena semakin besar ROA suatu bank, maka semakin besar pula tingkat keuntungan yang dicapai bank tersebut dan semakin baik pula posisi bank tersebut dari segi penggunaan aset.

c. Sebaiknya Perusahaan selalu menjaga keseimbangan antara dana masyarakat yang berhasil dikumpulkan oleh bank dengan jumlah kredit yang diberikan kepada masyarakat atau pihak lainnya agar tidak terjadi dana yang menganggur karena berdasarkan pembahasan pemberian kredit merupakan penyumbang besar terhadap peningkatan profitabilitas, hal ini merupakan pengaruh pemberian kredit terghadap profitabilitas tersebut.

\section{DAFTAR PUSTAKA}

Agus Harjito \& Martono, (2010) "Manajemen Keuangan” Yogyakarta: Penerbit Ekonisia. Agus Sartono. (2010). "Manajemen Keuangan Toeri dan Aplikasi”, Edisi keempat, Yogyakarta: Penerbit BPFE.

Akbar, Irfan Rizka,. (2018) Analisis Kebijakan Kepala Sekolah Dalam Upaya Meningkatkan Kompetensi Guru (Study Kasus Pada Smk Muhammadiyah Parung). Masters thesis, Universitas Pamulang. 
Algifari. (2015). “Analisis Regresi untuk Bisnis dan Ekonomi”. Yogyakarta: BPFE.

Fahmi, Irham (2012), "Pengantar Manajemen Keuangan” Cetakan pertama. Bandung: Penerbit Alfabeta.

Hidayat, A., \& Sunarsi, D. (2020). Faktor-Faktor Yang Mempengaruhi Dana Pihak Ketiga Dan Dampaknya Terhadap Profitabilitas (Survey Pada Bpr Syariah Di Jawa Barat Tahun 2014-2017). Jurnal Proaksi, 7(1), 54-65.

Imam Ghozali (2017). “Aplikasi Analisis Multivariate Dengan Program SPSS”. Edisi Kelima. Semarang: Badan Penerbit Undip.

Istijanto (2014) "Riset Sumber Daya Manusia". Jakarta: PT. Gramedia Pustaka

Jasmani, J. (2018). Pengaruh Kinerja Keuangan Terhadap Harga Saham (Analisis Pada Perusahaan Property dan Real Estate Yang Go Public di Bursa Efek Indonesia. Jurnal Akuntansi Indonesia, 12(2).

Jasmani, J. (2019). The Effect of Liquidity and Working Capital Turnover on Profitability at PT. Sumber Cipta Multiniaga, South Jakarta. PINISI Discretion Review, 3(1), 2938.

Kasmir (2010), “Analisis Laporan keuangan”, penerbit raja grafindo persada, Jakarta

Kasmir. (2012) "Pengantar Manajemen Keuangan”, Edisi Pertama, Cetakan kedua, Jakarta: Prenada Media.

Martono dan Agus Harjito, (2011). "Manajemen Keuangan”, Jakarta: Penerbit Ekonisia.

Munawir (2010), “Analisis Laporan Keuangan”, Edisi Ke Empat, Penerbit Liberty, Yogyakarta.

Rozi, A., Agustin, F., Hindriari, R., Rostikawati, D., \& Akbar, I. R. (2020). The Effect Of Leadership On Employee Performance at PT. Stella Satindo In Jakarta. HUMANIS (Humanities, Management and Science Proceedings), 1(1).

Santoso, Singgih (2015). "Menguasai Statistik Multivariat". Jakarta: PT Elex Media Komputindo.

Sartono, "Manajemen Keuangan Aplikasi Dan Teori”, Edisi Keempat, BPFE, Yogyakarta, 2008.

Sarwani, S., Akbar, I. R., Handoko, A. L., \& Ilham, D. (2020). Pengaruh Pelatihan dan Motivasi terhadap Produktivitas Kerja Karyawan pada PT. Lion Mentari Airlines Bandara Internasional Soekarno Hatta Cengkareng. Jurnal Ilmu Komputer dan Bisnis, 11(2a), 91-100.

Sawir, (2003). "Analisis Kinerja Keuangan dan Perencanaan Keuangan Perusahaan", Cetakan ketiga, Jakarta: Penerbit PT. Gramedia Pustaka Utama.

Sugiyarso, G. dan F. Winarni, "Manajemen Keuangan (Pemahaman Laporan Keuangan, Pengelolaan Aktiva, Kewajiban dan Modal serta Pengukuran

Sugiyono (2017), "Metode Penelitian Administrasi : dilengkapi dengan Metode R \& D". Bandung: Alfabeta. 